\title{
Mental Symptoms and Drug Use in Maintenance Treatment with Slow-Release Oral Morphine Compared to Methadone: Results of a Randomized Crossover Study
}

\author{
Uwe Verthein ${ }^{\mathrm{a}}$ Thilo Beck $^{\mathrm{b}}$ Christian Haasen ${ }^{\mathrm{a}} \quad$ Jens Reimer ${ }^{\mathrm{a}}$

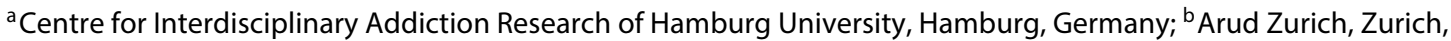 \\ Switzerland
}

\section{Key Words}

Opioid maintenance treatment . Slow-release oral morphine $\cdot$ Methadone $\cdot$ Mental symptoms . Concomitant drug use $\cdot$ Treatment satisfaction

\begin{abstract}
Background: Opioid maintenance treatment is the option of choice to stabilize opioid-dependent patients. Whilst efficacy of methadone and buprenorphine has been studied extensively, fewer data on slow-release oral morphine are available. Aims: This study analyzes the effects of slow-release oral morphine compared to methadone with regard to self-reported mental symptoms, drug use and satisfaction with treatment. Methods: The study was carried out as an open-label randomized crossover trial in 14 treatment sites in Switzerland and Germany. It comprised 2 crossover periods of 11 weeks each. For measuring mental symptoms, the Symptom Checklist-27 (SCL-27) was used. Drug and alcohol use was assessed by the number of consumption days, and treatment satisfaction by a visual analogue scale. Results: A total of 157 patients were included for the analyses (per-protocol sample). Statistically significantly better outcomes for morphine as compared to methadone treatment were found for overall severity of mental symptoms (SCL-27 Global Severity Index), as well as 5 of the 6 syndrome groups of the $\mathrm{SCL}-27$, and for treatment satisfaction. There were no statis-
\end{abstract}

tically significant differences with regard to drug or alcohol use between groups. Conclusions: This study supports positive effects of slow-release oral morphine compared to methadone on patient-reported outcomes such as mental symptoms and treatment satisfaction with comparable effects on concomitant drug use. Slow-release oral morphine represents a meaningful alternative to methadone for treatment of opioid dependence.

(c) 2014 S. Karger AG, Basel

\section{Introduction}

Opioid maintenance treatment aims to ensure survival, decrease illicit substance use, and increase patients' health and functioning [1]. Opioid agonists used in maintenance treatment include methadone, buprenorphine, levomethadone hydrochloride/levomethadyl acetate, diacetylmorphine, (dihydro-)codeine, and (slow-release oral) morphine. Whilst efficacy in terms of treatment retention and substance use has been studied extensively for methadone and buprenorphine, there are fewer data on patient-reported outcomes [2]. This is particularly true for diacetylmorphine and slow-release oral morphine, two medications which are increasingly used in Europe [3-5]. From a pharmacological perspective, morphine seems to be particularly suitable for opioid mainte-

\begin{tabular}{|c|c|}
\hline KARGER 125: & $\begin{array}{l}\text { (c) } 2014 \text { S. Karger AG, Basel } \\
1022-6877 / 14 / 0212-0097 \$ 39.50 / 0\end{array}$ \\
\hline $\begin{array}{l}\text { E-Mail karger@karger.com } \\
\text { www.karger.com/ear }\end{array}$ & $\begin{array}{l}\text { This is an Open Access article licensed under the terms of the } \\
\text { Creative Commons Attribution-NonCommercial 3.0 Un- } \\
\text { ported license (CC BY-NC) (www.karger.com/OA-license), } \\
\text { applicable to the online version of the article only. Distribu- } \\
\text { tion permitted for non-commercial purposes only. }\end{array}$ \\
\hline
\end{tabular}

Dr. Uwe Verthein

Centre for Interdisciplinary Addiction Research of Hamburg University, CIAR University Medical Center Hamburg-Eppendorf, Department of Psychiatry and Psychotherapy, Martinistrasse 52, DE-20246 Hamburg (Germany)

E-Mail u.verthein@uke.uni-hamburg.de 
Fig. 1. Crossover study design over 47 weeks ( $\mathrm{R}=$ randomization); assessments at week 0 (baseline), 2, 6, 11, 13, 17 and 22.

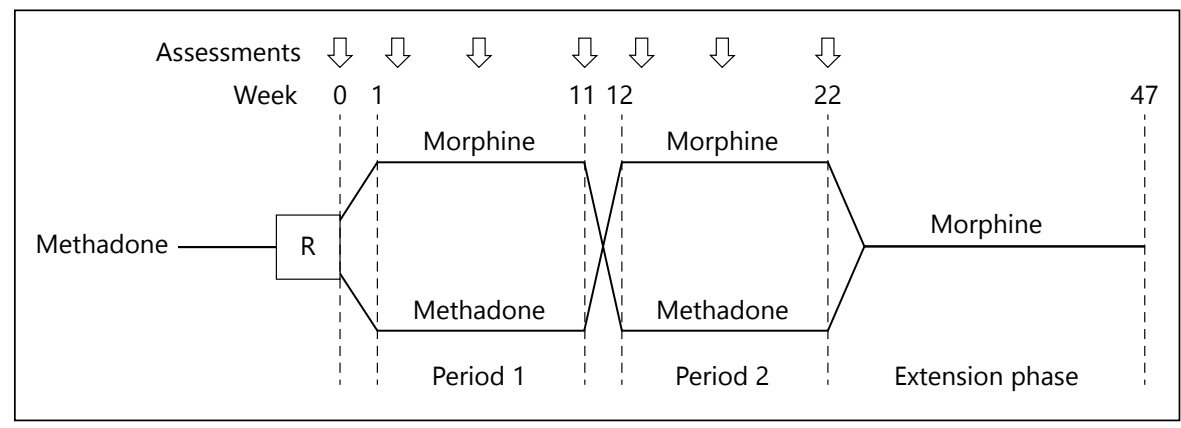

nance treatment, as it largely has the same properties as the substituted drug heroin/diacetylmorphine. The short half-life of morphine, a therapeutic limitation, has been overcome by a slow-release formulation $[6,7]$.

In several studies, slow-release oral morphine has been proven as an efficacious medication for reduction of illicit drug use, with effects similar to methadone maintenance treatment $[3,8-10]$. Given the high prevalence rates of psychiatric comorbidity in opioid-dependent patients, the effects of substitution medication on these symptoms in particular are of special interest [11]. Previous studies suggest positive effects of slow-release oral morphine on depression, anxiety or quality of life $[9,10,12]$. However, only the study of Eder et al. [9] had a controlled design, and it failed to show superior quality of life results for slow-release oral morphine compared to methadone [13].

A recent crossover trial confirmed the noninferiority of slow-release oral morphine regarding the additional use of heroin compared to methadone [8]. This report focuses on the results of patient-reported outcomes from the study, which were secondary efficacy-related parameters. The effects of slow-release oral morphine compared to methadone on mental symptoms as well as self-reported drug and alcohol use and satisfaction with treatment are described.

\section{Methods}

An open-label randomized crossover study was conducted in 14 treatment sites in Switzerland and Germany. For study inclusion, patients had to be opioid dependent (F11.2 according to ICD10 ), aged 18 years or older and already participating in methadone maintenance treatment for at least 26 weeks. The study design is described in detail elsewhere [see 8]. The main part of the study comprised two crossover periods of 11 weeks each ( 1 week adjustment phase followed by 10 weeks of treatment; see fig. 1).

Self-reported outcomes were assessed during the crossover phase, i.e. at baseline, weeks 2, 6 and 11 during the 1st period and at weeks 13, 17 and 22 during the 2 nd period (see fig. 1). Mental symptoms were rated according to the Symptom Checklist-27
(SCL-27), a short form of the SCL-90-R [14]. This instrument includes subscales on depressive, vegetative and agoraphobic symptoms as well as a global severity index (GSI), which represents an overall burden of psychiatric symptoms. Drug and alcohol use at the time of inclusion were assessed according to the European Addiction Severity Index standards [15]. The number of self-reported consumption days during the past 30 days at baseline and during the time span since last assessment (at weeks 2, 6, 11 and 13, 17, 22) was used for analyses. Treatment satisfaction was assessed by a visual analogue scale (VAS) scoring from 0 ('not satisfied at all') to 10 ('deeply contented').

To increase the validity of the study results, stringent criteria for the per protocol (PP) population were set to include patients who completed each of the two crossover treatment periods (11 weeks) within a specified time frame of $\geq 70$ days and $\leq 84$ days, who had urinalyses for $\geq 9$ out of 11 weeks per crossover period and no discontinuation of study medication for more than 5 consecutive days [see 8].

For statistical analyses regarding the PP population, the results of the 3 assessments of each criterion were pooled by calculating a mean score per period for both treatment conditions. With regard to drug (heroin, cocaine, benzodiazepines) or alcohol use, overall sum scores of consumption days per period were calculated. These scores were compared by multifactorial analysis of variance with factors for treatment, sequence and period. Equality of the carry-over effect was tested by a two-sample $t$ test. Statistical analyses were performed using SPSS, version 19 [16]. For the statistical analyses in the intention to treat (ITT) population, the mean values from available data were calculated for each period of treatment.

This study was approved by the national and regional ethics committees and conducted in accordance with the Declaration of Helsinki, the International Conference on Harmonisation Guideline for Good Clinical Practice, and the European Union Clinical Trials Directive 2001/20/EC. This clinical trial has been registered with ClinicalTrials.gov, No. NCT01079117, and EudraCT, No. 2008-002185-60.

\section{Results}

A total of 276 patients (ITT sample) were recruited and randomly assigned to a treatment sequence starting either with morphine and followed by methadone (group 1) or 


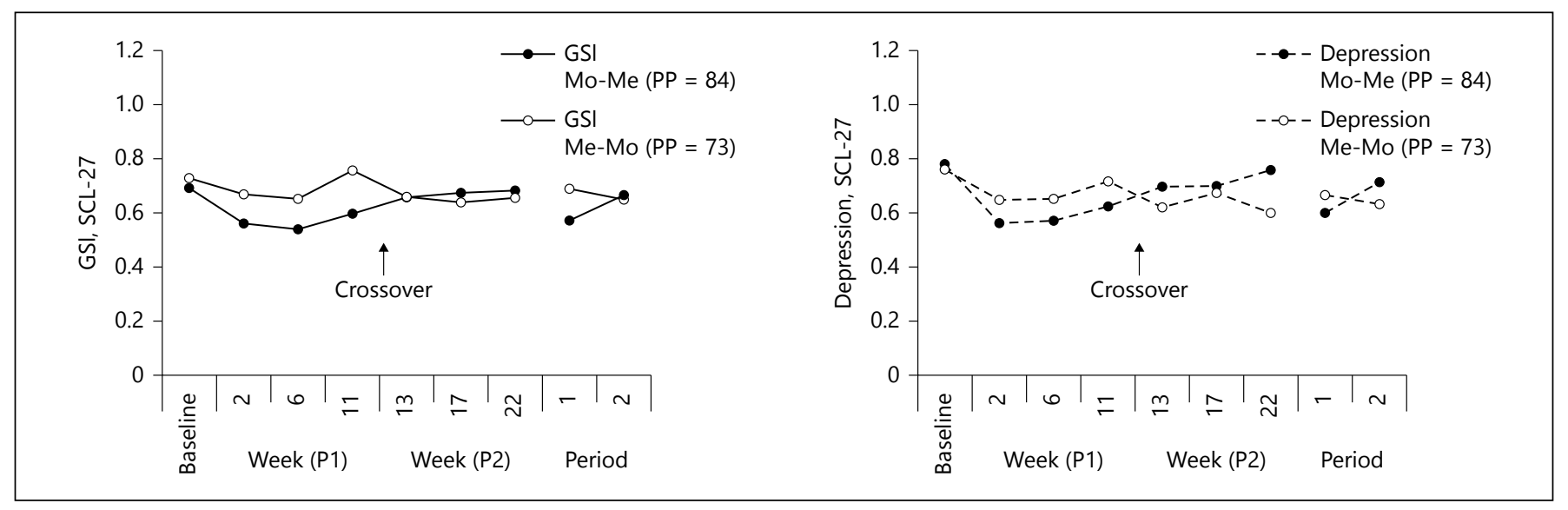

Fig. 2. Mental symptoms (SCL-27) over 22 weeks per period by study arm.

methadone followed by morphine (group 2). Retention in treatment during crossover was high without any differences between treatments or periods [group 1: 110 of 141 patients (78\%); group 2: 101 of 135 patients (75\%)] [8]. One hundred and fifty-seven patients qualified for the PP population: 84 patients in group 1 (morphine-methadone) and 73 patients in group 2 (methadone-morphine) [see 8].

\section{Sample Characteristics}

Most patients in the PP sample were male, single and unemployed, and mean age was 39 years. The average length of methadone substitution treatment before study entry was 3.6 years. Although some differences in the baseline characteristics between study populations were recorded, e.g. rates of hepatitis $C$ virus infection, cocaine use and psychiatric comorbidity (table 1), they were considered not to be relevant confounders when comparing the two treatment groups.

\section{Mental Symptoms}

Mental symptoms as rated by SCL-27 had a different time course during the two sequences of treatment. Baseline values were similar in both treatment arms (sequences). Symptom severity (as measured by GSI) decreased in the methadone-morphine arm after the medication switch, whereas it increased in the morphine-methadone arm (fig. 2, left side). Similar results were obtained for depressive symptoms (as measured by the relevant SCL-27 subscale); whilst under morphine treatment, patients reported fewer symptoms compared to the methadone treatment period (fig. 2, right side).

Overall severity of mental symptoms (GSI) was lower under morphine compared to methadone treatment, and
Table 1. Sample characteristics at baseline

\begin{tabular}{lll}
\hline Characteristic & $\begin{array}{l}\text { ITT } \\
\text { sample }\end{array}$ & $\begin{array}{l}\text { PP } \\
\text { sample }\end{array}$ \\
\hline $\begin{array}{ll}\text { Males, \% } \\
\text { Age, years }\end{array}$ & 81.5 & 84.1 \\
Civil status, single, \% & $38.1 \pm 7.6$ & $38.9 \pm 7.4$ \\
Employed, working & 74.6 & 77.7 \\
$\quad$ & & \\
$\quad$ (part-time or full-time), \% & 23.2 & 17.8 \\
Length of prior substitution treatment, & & \\
$\quad$ years & $3.9 \pm 4.4$ & $3.6 \pm 4.4$ \\
Pre-treatment: last methadone dose, mg & $98.0 \pm 40.0$ & $92.0 \pm 30.8$ \\
Alcohol use: EuropASI composite score & $0.12 \pm 0.17$ & $0.12 \pm 0.18$ \\
Drug use: EuropASI composite score & $0.31 \pm 0.14$ & $0.31 \pm 0.15$ \\
Age at first heroin use, years & $20.3 \pm 5.1$ & $20.5 \pm 5.1$ \\
Cocaine use, \% & 48.2 & 68.8 \\
Body mass index, kg/m ${ }^{2}$ & $25.2 \pm 4.4$ & $24.8 \pm 4.2$ \\
HIV positive, \% & 3.6 & 4.5 \\
Hepatitis C positive, \% & 57.7 & 67.3 \\
Psychiatric comorbidity, \% & 69.2 & 57.3 \\
GSI (SCL-27) & $0.72 \pm 0.63$ & $0.71 \pm 0.61$ \\
Total & 276 & 157 \\
\hline
\end{tabular}

Values are expressed as mean \pm SD unless otherwise indicated.

the difference was statistically significant in the PP population (table 2$)$ as well as in the ITT population $(0.60 \pm 0.60$ under morphine vs. $0.67 \pm 0.63$ under methadone; $\mathrm{p}<$ $0.05)$. In addition, 5 of the 6 syndrome groups represented by subscales of SCL-27 showed better outcomes for morphine as compared to methadone treatment. Differences between treatment groups were most prominent for depressive and dysthymic symptom subscales (table 2). Generally, patients under oral morphine treatment displayed 
Table 2. Mental symptoms (SCL-27), drug and alcohol use (number of days, self-reported) and treatment satisfaction (VAS, 0-10) by treatment, controlled for sequence, period and carry-over effect

\begin{tabular}{|c|c|c|c|c|c|}
\hline & \multirow[t]{2}{*}{ Morphine } & \multirow[t]{2}{*}{ Methadone } & \multicolumn{3}{|c|}{ Significance } \\
\hline & & & F value & $\mathrm{p}$ value & t value \\
\hline \multicolumn{6}{|l|}{ Mental symptoms (SCL-27) } \\
\hline GSI & $0.61 \pm 0.56$ & $0.68 \pm 0.60$ & 6.91 & $<0.01$ & \\
\hline Sequence effect & & & 3.90 & 0.050 & \\
\hline Period effect & & & 1.44 & 0.233 & \\
\hline Carry-over effect & & & & 0.582 & -0.551 \\
\hline Depression & $0.62 \pm 0.69$ & $0.70 \pm 0.75$ & 5.07 & $<0.05$ & \\
\hline Sequence effect & & & 0.03 & 0.858 & \\
\hline Period effect & & & 1.54 & 0.216 & \\
\hline Carry-over effect & & & & 0.957 & 0.055 \\
\hline Dysthymic symptoms & $0.77 \pm 0.70$ & $0.86 \pm 0.77$ & 4.97 & $<0.05$ & \\
\hline Sequence effect & & & 3.89 & 0.050 & \\
\hline Period effect & & & 3.84 & 0.052 & \\
\hline Carry-over effect & & & & 0.495 & -0.685 \\
\hline Vegetative symptoms & $0.61 \pm 0.56$ & $0.69 \pm 0.61$ & 4.41 & $<0.05$ & \\
\hline Sequence effect & & & 0.00 & 0.954 & \\
\hline Period effect & & & 0.36 & 0.551 & \\
\hline Carry-over effect & & & & 0.980 & 0.025 \\
\hline Agoraphobic symptoms & $0.32 \pm 0.46$ & $0.37 \pm 0.54$ & 4.99 & $<0.05$ & \\
\hline Sequence effect & & & 4.19 & $<0.05$ & \\
\hline Period effect & & & 3.20 & 0.076 & \\
\hline Carry-over effect & & & & 0.538 & -0.617 \\
\hline Sociophobic symptoms & $0.59 \pm 0.69$ & $0.64 \pm 0.72$ & 4.17 & $<0.05$ & \\
\hline Sequence effect & & & 28.84 & $<0.001$ & \\
\hline Period effect & & & 0.00 & 0.943 & \\
\hline Carry-over effect & & & & 0.206 & -1.269 \\
\hline Symptoms of mistrust & $0.83 \pm 0.82$ & $0.89 \pm 0.85$ & 3.28 & 0.072 & \\
\hline Sequence effect & & & 5.05 & $<0.05$ & \\
\hline Period effect & & & 0.00 & 0.983 & \\
\hline Carry-over effect & & & & 0.596 & -0.531 \\
\hline \multicolumn{6}{|l|}{ Substance use } \\
\hline Heroin & $6.4 \pm 11.7$ & $6.4 \pm 11.3$ & 0.01 & 0.936 & \\
\hline Sequence effect & & & 2.19 & 0.141 & \\
\hline Period effect & & & 0.41 & 0.521 & \\
\hline Carry-over effect & & & & 0.544 & -0.608 \\
\hline Cocaine & $2.4 \pm 6.0$ & $2.2 \pm 6.2$ & 0.49 & 0.483 & \\
\hline Sequence effect & & & 9.38 & $<0.01$ & \\
\hline Period effect & & & 0.24 & 0.626 & \\
\hline Carry-over effect & & & & 0.289 & -1.063 \\
\hline Benzodiazepines & $8.2 \pm 17.4$ & $7.4 \pm 15.8$ & 1.18 & 0.279 & \\
\hline Sequence effect & & & 3.21 & 0.075 & \\
\hline Period effect & & & 0.51 & 0.477 & \\
\hline Carry-over effect & & & & 0.611 & -0.509 \\
\hline Alcohol & $14.5 \pm 21.7$ & $14.5 \pm 20.8$ & 0.00 & 0.995 & \\
\hline Sequence effect & & & 7.15 & $<0.01$ & \\
\hline Period effect & & & 0.03 & 0.864 & \\
\hline Carry-over effect & & & & 0.377 & -0.886 \\
\hline \multicolumn{6}{|l|}{ Treatment satisfaction } \\
\hline Satisfaction & $7.6 \pm 1.8$ & $6.0 \pm 2.2$ & 44.37 & $<0.001$ & \\
\hline Sequence effect & & & 0.05 & 0.824 & \\
\hline Period effect & & & 9.63 & $<0.01$ & \\
\hline Carry-over effect & & & & 0.813 & -0.237 \\
\hline Total & 157 & 157 & & & \\
\hline
\end{tabular}


Fig. 3. Drug and alcohol use per period by study arm; mean number of self-reported consumption days (sum of consumption days per period).

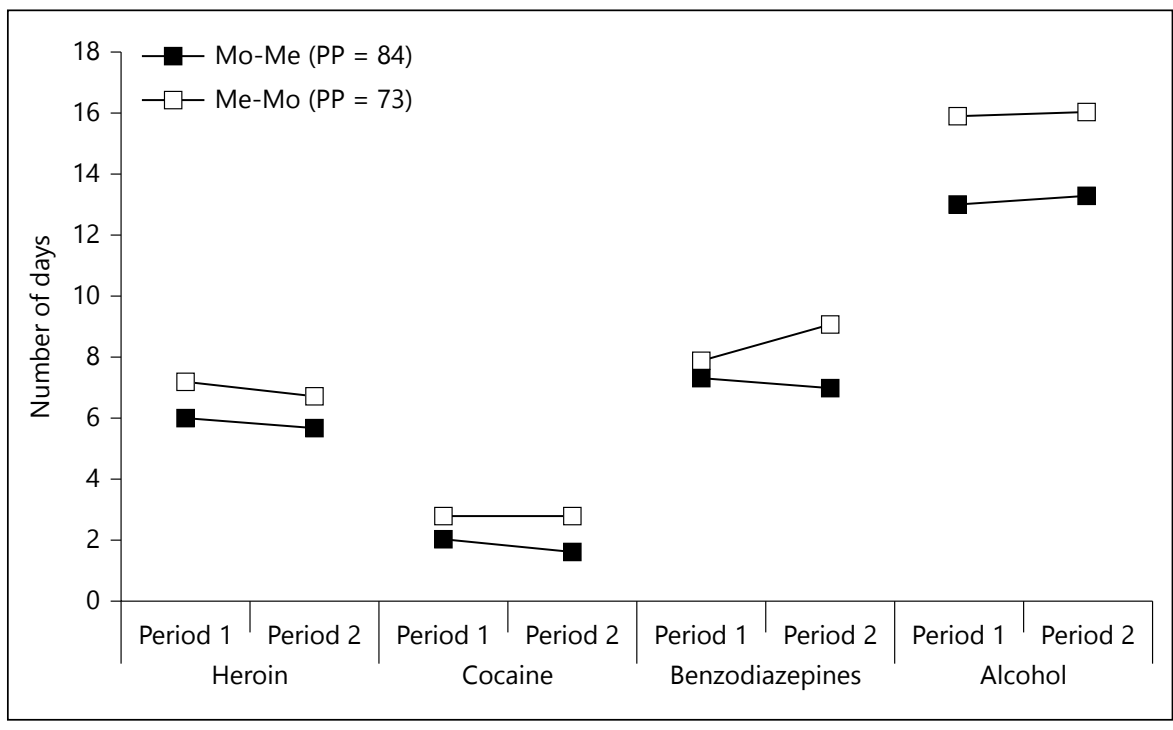

better mental health than when under methadone treatment. In some of the subscales, e.g. those related to symptoms of agoraphobia, sociophobia and mistrust, an interfering effect of sequence was observed, indicating different symptom levels between group 1 and group 2, i.e. generally higher scores in the methadone-morphine arm, as represented by the GSI scores (see fig. 2). The tests for a possible carry-over effect regarding SCL-27 GSI and subscales did not show statistical significance.

\section{Drug and Alcohol Use}

The highest number of consumption days was found for alcohol, followed by benzodiazepines, heroin and cocaine. There were no statistically significant differences in substance use according to the treatment condition (morphine vs. methadone). Switching from morphine to methadone or vice versa had no effect on substance use, except for an increase in benzodiazepine use in the methadonemorphine arm (fig. 3). The average number of consumption days of heroin, cocaine, benzodiazepines and alcohol remained similar in both study periods. However, patients starting with methadone and switching to morphine had generally higher consumption levels in both periods.

This stable consumption pattern is reflected in the statistical analyses of the comparison of the mean number of consumption days between the treatment conditions. The comparison for treatment groups did not reveal a statistically significant difference for any substance (table 2). For the use of cocaine and alcohol, a significant sequence effect was detected. This finding corresponds to an overall higher consumption in the methadone-mor- phine subsample in both study periods. Again, the tests for possible carry-over effects yielded no statistically significant differences.

\section{Satisfaction with Treatment}

Initially, treatment satisfaction increased under both treatment conditions (morphine and methadone). However, after switching from morphine to methadone, treatment satisfaction decreased, whereas it increased further in patients who switched from methadone to morphine. In both periods, patients described higher treatment satisfaction under treatment with morphine compared to methadone (fig. 4).

Treatment satisfaction was statistically significantly in favor of morphine (table 2). Furthermore, the period effect reached statistical significance, which is reflected by an overall higher treatment satisfaction in the first period (see fig. 4). There was no significant carry-over effect regarding treatment satisfaction. Higher satisfaction under morphine treatment was also reported in the ITT population $(7.66 \pm 2.21$ under morphine vs. $6.01 \pm 2.50$ under methadone; $\mathrm{p}<0.001)$.

\section{Discussion}

In this open-label, randomized, crossover trial, the effects of morphine substitution treatment were analyzed using a robust methodology with regard to self-reported mental symptoms, drug use and treatment satisfaction. Treatment with slow-release oral morphine was associ- 
Fig. 4. Satisfaction with treatment (VAS) over 22 weeks per period by study arm.

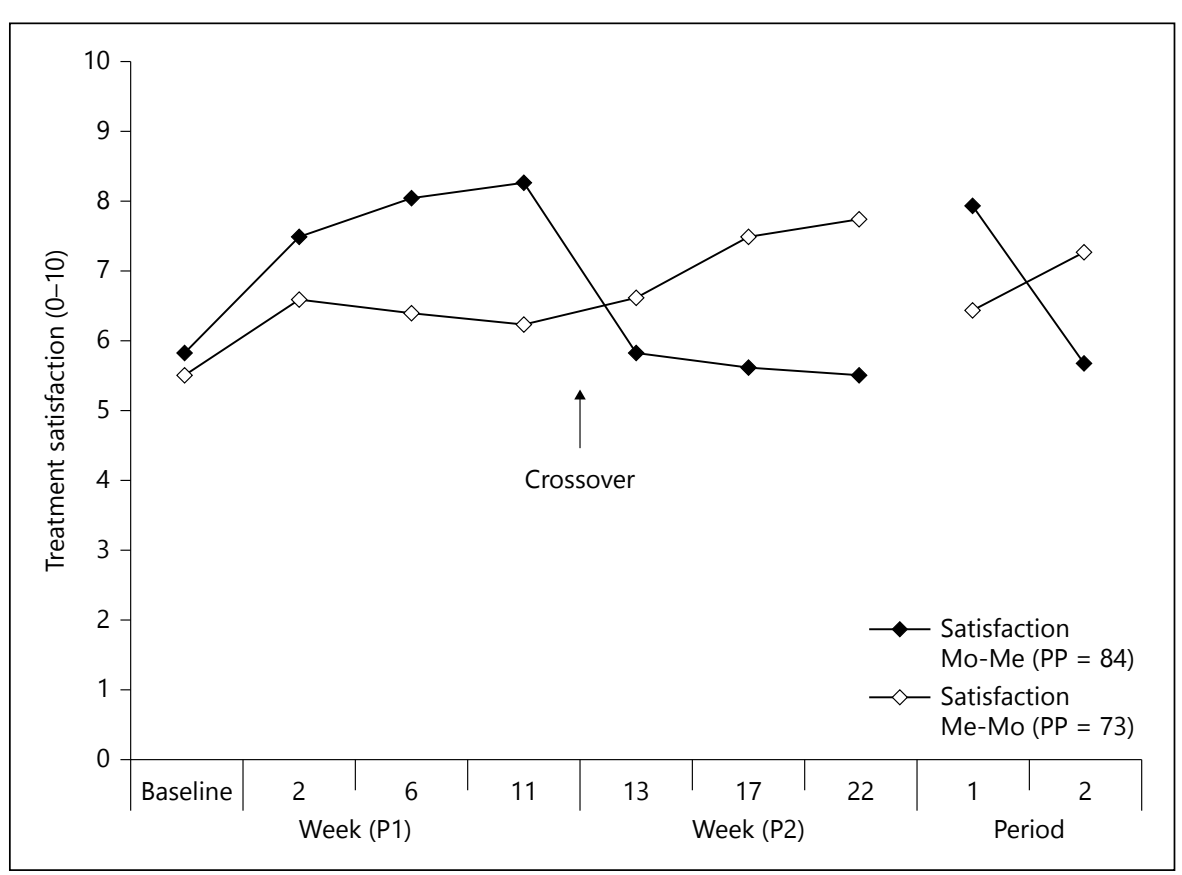

ated with less overall severity of mental symptoms, as well as less severity for specific mental health outcomes such as depression, dysthymic symptoms, vegetative symptoms, agoraphobic symptoms and sociophobic symptoms compared to methadone treatment. Furthermore, treatment satisfaction was significantly better under morphine treatment compared to methadone. Advantages of morphine over methadone were evident not only in the PP but also in the ITT population. Similar differences in treatment effects were observed in patients who previously received methadone and were switched to slow-release oral morphine [10].

No significant differences between morphine and methadone treatment were noted with regard to co-consumption of heroin, cocaine, benzodiazepines or alcohol. Previous findings have suggested the efficacy of methadone in reducing opioid cravings over $24 \mathrm{~h}$, but without sufficient stabilization of mood disturbances over this time period. This finding was related to the pharmacokinetic properties of methadone and its differential effects on mood and withdrawal suppression [17]. In a comparative study, slow-release oral morphine produced a later plasma peak than methadone, which could explain the better subjective efficacy with respect to withdrawal and mental symptoms over a 24-hour period [7]. However, in this study the dose level of morphine was comparatively low (methadone/morphine conversion factor 1:4.6) in order to reach an adequate substitution effect. Advantag- es of morphine over methadone in terms of depression, anxiety and quality of life have been described before [9, 13], but only one study followed a controlled design [9]. However, that study failed to find superior quality of life outcomes in the morphine group, likely due to the small sample size and low statistical power. Our study provides additional clinical evidence for a superior effect of slowrelease oral morphine on improvement of psychiatric symptoms compared to methadone, and was conducted using a relatively large and controlled study design. Since a flexible dose regimen was used in both treatment conditions and average doses of morphine and methadone (based on a ratio of about 7.6:1) were similar [see 8], the observed effects may be associated with the intrinsic pharmacological profile of the treatments.

Treatment goals have seen a shift from a paternalistic model of delivery of care to a more patient-centered approach in recent years [18]. In this context, the concept of shared decision making and patient satisfaction has become even more important. Whilst in addiction medicine, shared decision making faces some disease-inherent and legal boundaries, satisfaction with treatment as a preference for specific substitution medication should be considered in daily practice in order to improve the chances of achieving treatment goals in this difficult-totreat population. In our study, patient satisfaction was considerably higher with slow-release oral morphine as compared to methadone. 
Some limitations should be mentioned. Although patients enrolled in this study were already under methadone maintenance treatment, motives for treatment switch were not evaluated. Patients may have been either dissatisfied by ongoing (methadone) treatment or were curious to experience an alternative treatment which is currently under clinical evaluation. The SCL-27 scale - a short form of the well-established symptom check list SCL-90 [14, 19] - was used because of the availability of a validated translation into German and the fact that the short version is less burdensome to administer without loss of sensitivity of change [20]. The SCL-27 has acceptable psychometric properties which were found for the overall GSI score as well as for the subscales in studies with clinical and nonclinical samples [21, 22] (which is also true for the further developed version SCL-27-plus [23]). Other instruments for assessing psychological distress are not well established in the target population of opioid-dependent persons. Treatment satisfaction assessed by VAS may have some limitations, but has the advantage of providing a clear and simple measure. Alternative instruments, e.g. the Treatment Satisfaction Questionnaire for Medications-9, are more general as they combine effectiveness, side effects, convenience and global satisfaction. Although the latter dimension in this questionnaire is based on three items, one may question their power compared to a simplified unbiased and straightforward VAS [24].

A sequence effect was observed with regard to mental symptoms as well as to cocaine and alcohol consumption, with a stronger symptom load and more substance use in the methadone-morphine arm (group 2). Wide standard deviations in comparison to the means suggest that these effects may have mathematical rather than clinical relevance. With regard to self-reported cocaine use, no chang- es were seen in the methadone-morphine sequence (group 2 ) and there was some reduction of use in the morphinemethadone sequence (group 1). Higher use of alcohol was reported in both sequences of treatment, although levels were highest in the methadone-morphine sequence (group 2). A period effect was seen, such that an overall decrease in treatment satisfaction was apparent as the time in study progressed. Despite some inconsistent effects regarding sequences and periods, no statistically significant carry-over effects were seen in any parameter tested. This confirms the validity of the findings of this study.

In the context of patient-centered medicine, our data support a positive effect of slow-release oral morphine compared to methadone on patient-reported outcomes such as mental symptoms and treatment satisfaction, with similar effects on concomitant drug use. Slow-release oral morphine therefore represents a meaningful alternative to methadone for the treatment of chronic opioid dependence.

\section{Acknowledgement}

We thank patients and staff who participated in the study for their support. This study was sponsored by Mundipharma Medical Company, Basel, Switzerland.

\section{Disclosure Statement}

The authors report no conflicts of interest. The clinical trial was designed and financed by Mundipharma Medical Company, Basel, and conducted by qualified investigators under the sponsorship of Mundipharma Medical Company. All authors are independent of any significant financial or other relationship to the sponsor, except for appropriate compensation for the conduct of this study and related expenditure.

\section{References}

$1 \mathrm{WHO} / \mathrm{UNDOC} / \mathrm{UNAIDS}$ position paper. www.who.int/substance_abuse/publications/ en/PositionPaper_flyer_English.pdf, 2004.

-2 Mattick RP, Kimber J, Breen C, Davoli M: Buprenorphine maintenance versus placebo or methadone maintenance for opioid dependence. Cochrane Database Syst Rev 2008;2: CD002207.

3 Jegu J, Gallini A, Soler P, Montastruc J-L, Lapeyre-Mestre M: Slow-release oral morphine for opioid maintenance treatment: a systematic review. Br J Clin Pharmacol 2011;71:832843.

4 Ferri M, Davoli M, Perucci CA: Heroin maintenance for chronic heroin-dependent indi- viduals. Cochrane Database Syst Rev 2011;12: CD003410.

5 Ferri M, Minozzi S, Bo A, Amato L: Slow-release oral morphine as maintenance therapy for opioid dependence. Cochrane Database Syst Rev 2013;6:CD009879.

-6 Broomhead A, West R, Eglinton L, Jones M, Bubner R, Sienko D, Knox K: Comparative single-dose pharmacokinetics of sustained-release and modified-release morphine sulphate capsules under fed and fasting conditions. Clin Drug Investig 1997;13: 162-170.

7 Mitchell TB, White J, Somogyi AA, Bochner F: Comparative pharmacodynamics and pharmacokinetics of methadone and slow-release oral morphine for maintenance treatment of opioid dependence. Drug Alcohol Depend 2003;72:85-94.

$>8$ Beck T, Haasen C, Verthein U, Walcher S, Schuler C, Backmund M, Ruckes C, Reimer J: Maintenance treatment for opioid dependence with slow-release oral morphine: a randomized cross-over study versus methadone. Addiction 2014;109:617-626.

$>$ Eder H, Jagsch R, Kraigher D, Primorac A, Ebner N, Fischer G: Comparative study of the effectiveness of slow-release morphine and methadone for opioid maintenance therapy. Addiction 2005; 100:1101-1109.
Mental Symptoms in Treatment with Slow-Release Oral Morphine 
10 Kastelic A, Dubajic C, Strbad E: Slow-release oral morphine for maintenance treatment of opioid addicts intolerant to methadone or with inadequate withdrawal suppression. Addiction 2008;103:1837-1846.

-11 Reimer J, Verhein U, Karow A, Schäfer I, Naber D, Haasen C: Physical and mental health in severe opioid-dependent patients within a randomized controlled maintenance trial. Addiction 2011;106:1647-1655.

-12 Vasilev GN, Alexieva DZ, Pavlova RZ: Safety and efficacy of oral slow-release morphine for maintenance treatment in heroin addicts: a 6-month open noncomparative study. Eur Addict Res 2006;12:53-60.

13 Winklbaur B, Jagsch R, Ebner N, Thau K, Fischer G: Quality of life in patients receiving opioid maintenance therapy. A comparative study of slow-release morphine versus methadone treatment. Eur Addict Res 2008;14:99105.

14 Hardt J, Egle UT, Kappis B, Hessel A, Brähler E: Die Symptom-Checkliste SCL-27 - Ergebnisse einer deutschen Repräsentativbefragung. Psychother Psychosom Med Psychol 2004;54:214-223.
15 Kokkevi A, Hartgers C: EuropASI: European adaptation of a multidimensional assessment instrument for drug and alcohol dependence. Eur Addict Res 1995;1:208-210.

16 SPSS Inc: IBM SPSS Statistics 19. Core-System-Manual, 1989, 2010.

17 Shiran MR, Lennard MS, Iqbal MZ, Lagundoye O, Seivewright N, Tucker GT, RostamiHodjegan A: Pharmacokinetic-pharmacodynamic modelling of mood and withdrawal symptoms in relation to plasma concentrations of methadone in patients undergoing methadone maintenance treatment. J Clin Psychopharmacol 2012;32:666-671.

18 Dwamena F, Holmes-Rovner M, Gaulden CM, Jorgenson S, Sadigh G, Sikorskii A, Lewin S, Smith RC, Coffey J, Olomu A: Interventions for providers to promote a patient-centred approach in clinical consultations. Cochrane Database Syst Rev 2012;12: CD003267.

19 Maremmani I, Pani PP, Pacini M, Perugi G: Substance use and quality of life over 12 months among buprenorphine maintenancetreated and methadone maintenance-treated heroin-addicted patients. J Subst Abuse Treat 2007;33:91-98.
20 Prinz U, Nutzinger DO, Schulz H, Petermann F, Braukhaus C, Andreas S: Comparative psychometric analyses of the SCL-90-R and its short versions in patients with affective disorders. BMC Psychiatry 2013;13:104.

21 Kuhl HC, Hartwig I, Petitjean S, MüllerSpahn F, Margraf J, Bader K: Validation of the Symptom Checklist SCL-27 in psychiatric patients: psychometric testing of a multidimensional short form. Int J Psychiatry Clin Pract 2010;14:145-149.

22 Hardt J, Dragan M, Kappis B: A short screening instrument for mental health problems: the symptom checklist-27 (SCL-27) in Poland and Germany. Int J Psychiatry Clin Pract 2011;15:42-49.

23 Kuncewicz D, Dragan M, Hardt J: Validation of the Polish version of the symptom-chscklist27-plus questionnaire. Psychiatr Pol 2014;48: 345-358.

24 Bharmal M, Payne K, Atkinson MJ, Desrosiers MP, Morisky DE, Gemmen E: Validation of an abbreviated Treatment Satisfaction Questionnaire for Medication (TSQM-9) among patients on antihypertensive medications. Health Qual Life Outcomes 2009;7:36. 